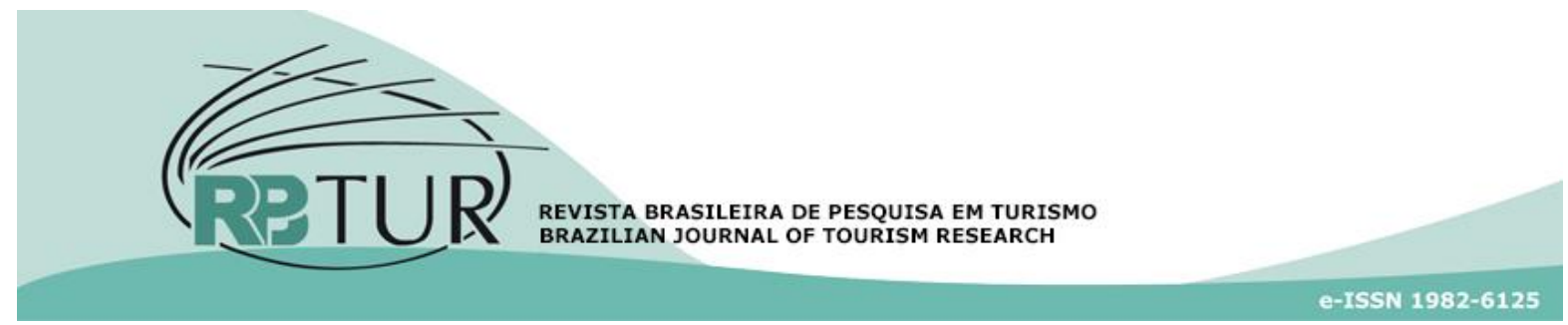

\title{
Artigos
}

\section{As leis da hospitalidade}

\section{The laws of hospitality}

\section{Las leyes de la hospitalidad}

\author{
Luiz Octávio de Lima Camargo ${ }^{1}$
}

1 Universidade de São Paulo (USP), São Paulo, SP, Brasil.

Palavras-chave:

Hospitalidade; Hospitabilidade;

Leis não escritas; Turismo.

Keywords:

Hospitality; Hospitableness; Unwritten laws; Tourism.

\section{Palabras clave:}

Hospitalidad;

Hospitabilidad

Leyes no escritas;

Turismo.

Revisado por pares

Recebido em: 20/07/2020.

Aprovado em: 22/11/2020.

Editor:

Glauber Eduardo de Oliveira Santos.

\section{Resumo}

Na sociedade de mobilidade crescente, que vem substituindo a sociedade à dominante sedentária, o contato com estranhos/estrangeiros/desconhecidos aumenta velozmente, alterando instituições basilares da sociedade como casa, vizinhança, família, trabalho. A garantia de ser bem recebido em todos os lugares para onde vamos torna-se uma necessidade. A urbanidade, o tratamento polido, mas impessoal não é mais suficiente. Crescem as reivindicações por uma hospitalidade mais carregada de calor humano. Mesmo no comércio, termos como customização, fidelização são marcas da aspiração de pessoalidade no encontro. A discussão desses temas é o contexto para o propósito deste artigo de, com base nas reflexões de Jacques Derrida, Marcel Mauss, Julian Pitt-Rivers e Anne Gotman, desvelar as quatro leis básicas da hospitalidade: a incondicionalidade, a reciprocidade, a assimetria e a compensação. Adicionalmente, pretende levantar outras questões que surgem à margem da atual discussão, em especial o caso do turismo.

\section{Abstract}

In an ever-growing mobile society, which is replacing the predominantly sedentary one, the contact with strangers/foreigners/outsiders increases rapidly, changing basic institutions of society such as home, neighborhood, family, work. The assurance of being welcomed everywhere we go becomes a need and a right. Urbanity, polite but impersonal treatment is no longer enough. Demands for a hospitality more filled with human warmth are growing. Even in commercial exchanges, terms such as customization, loyalty are signs of the desire for a more personal service encounter. The discussion of these themes is the background for this article which draws on the reflections of Jacques Derrida, Marcel Mauss, Julian Pitt-Rivers, and Anne Gotman, to unveil the four basic laws of hospitality: unconditionality, reciprocity, asymmetry, and compensation. Additionally, it intends to raise other issues that arise outside the current discussion, especially the case of tourism.

Resumen

En la sociedad de movilidad creciente que há estado sustituyendo a la sociedad por el dominante sedentario, el contacto con extraños / extranjeros / extraños aumenta rápidamente, cambiando las instituciones básicas de la sociedad, como el hogar, el vecindario, la familia y el trabajo. La garantía de ser bienvenido donde quiera que vayamos se convierte en una necesidad. La urbanidad, el trato cortés pero impersonal ya no es suficiente. Las demandas de una hospitalidad más cargada de calor humano están creciendo. Incluso en el comercio, términos como personalización, fidelización son marcas de la aspiración de personalidad en el encuentro. La discusión de estos temas es el contexto para el propósito de este artículo, basado en las reflexiones de Jacques Derrida, Marcel Mauss, Julian PittRivers y Anne Gotman, para revelar las cuatro leyes básicas de la hospitalidad: incondicionalidad, reciprocidad, asimetría y compensación. Además, tiene la intención de plantear otros problemas que surgen fuera de la discusión actual, especialmente el caso del turismo. 
Como citar: Camargo, L.O.L. (2021). As leis da hospitalidade. Revista Brasileira de Pesquisa

em Turismo, São Paulo, 15 (2), e-2112, maio/ago.

http://dx.doi.org/10.7784/rbtur.v15i2.2112

\section{INTRODUÇÃO}

Nas zonas rurais e pequenas cidades, onde a maioria dos brasileiros vivia até a década de 1960, as pessoas acabavam por criar algum tipo de conhecimento mútuo. Ademais, deslocavam-se pouco, podiam morar a vida inteira na mesma casa, ter a mesma vizinhança por gerações. Viajar era um luxo, um evento que demandava dias ou semanas de preparação. São obviedades da história, mas que servem para mostrar que o contato com o estranho era então menos corrente do que o atual.

Nos últimos 70 anos, mobilidade e velocidade, enquanto categorias de espaço e tempo, cresceram juntas. O espaço encurtou e a velocidade acelerou. Tecnologias de transporte e de comunicação imprimiram um ritmo vertiginoso às mudanças. Ainda não temos a cabine de teletransporte do Star Trek mas o turismo espacial já bate à nossa porta. 0 paradoxo é que já não existe o desconhecido no globo terrestre, mas o número de desconhecidos cresce assustadoramente nos contatos cotidianos.

Pode-se mesmo dizer que hoje, para alguém que trabalha fora de casa, constituem exceção os contatos em que reina a familiaridade. São cenas em que por vezes descortinamos calor humano em meio à inospitalidade e hostilidade dominantes (Camargo, 2015). E como cruzamos com desconhecidos! Imigrantes, refugiados, turistas são os desconhecidos mais evidentes e cada vez mais frequentes. 0 desconhecido mais desconcertante, contudo, é o aquele com quem cruzamos nos meios de transporte, nas empresas, nas repartições públicas. Esses contatos podem até ser polidos, porém mais formais, impessoais.

Viard (2005) resume a discussão: estamos saindo de um mundo predominantemente sedentário, em que era menor a necessidade de se pensar em hospitalidade, para uma sociedade de mobilidade crescente, na qual, pode-se dizer, a garantia de ser bem recebido em todos os lugares para onde vamos torna-se uma urgência. 0 mesmo Viard diz que na França de 1970, as pessoas se moviam em no máximo 7 km diários; em 2.000, a cifra já passava de trinta. É de se imaginar o crescimento de lá para cá. Nas áreas de comércio e serviços, o bem receber é um diferencial de competitividade.

Neste texto, a noção de hospitalidade é diretamente relacionada com acolhimento ao desconhecido, o que justifica a ousadia de pensar em fases e períodos históricos diferentes dos consagrados pelos historiadores. $\mathrm{Na}$ fase mais longa da aventura humana, o Paleolítico, esse contato era muito esporádico e a noção de hospitalidade não se justificava. Somente após a invenção da agricultura e pecuária, os diferentes povos passaram a distinguir entre locais (seres humanos) e estrangeiros (bárbaros) e, como sugere Benveniste (1975), todo desconhecido passou a ser gravado com a pergunta: "será um hóspede ou inimigo? Da hostilidade crescente emergiu a hospitalidade e suas leis.

O segundo momento aconteceu no alvorecer da Modernidade com o êxodo rural que cresceu ainda mais com a revolução industrial quando as cidades europeias incharam e derramaram-se fora das muralhas. 0 advento dos códigos de urbanidade (Elias, 1994), do contato polido mas impessoal como regra de relação interpessoal, marcou esse momento.

O terceiro teve início após a década de 1950, com o aumento da migração internacional e regional crescentes e do turismo de massa nascente. É um outro mundo, mais agitado e frenético e o avanço dos meios de comunicação contribuiu para a hipermobilidade atual (Urry, 2001; Augé, 2010). Neste cenário, a fórmula da urbanidade já se mostra esgotada. Hoje surge uma reivindicação original: mais calor humano. Entre parênteses: expressões aqui utilizadas como calor humano, autenticidade e mesmo convivialidade, sem o devido embasamento psicológico (que foge à ambição deste texto) não significam o mesmo que a cordialidade de Buarque de Holanda (1989) e somente fazem sentido aqui como oposição ao formalismo instituído na urbanidade conforme aqui conceituada ou à oposição indivíduo/crachá ou, no limite, ao euisso que Buber (1979) usou contra a coisificação do outro e sua transformação em número, ou ainda, como 
diz Guattari (1991), à serialização de consciências. Neste mundo hiperpovoado, cresce o desejo de ser acolhido como indivíduos único.

O propósito deste texto é discutir e aprofundar essas reflexões como pano de fundo para extrair o que é aqui chamado de leis da hospitalidade. Para tanto, vamos trazer as reflexões já conhecidas de autores de peso que já abordaram o problema, em especial os filósofos Immanuel Kant (1995), Jacques Derrida (1999) e os antropólogos Conrad Lashley (2015), Julian Pitt-Rivers (2012) e Anne Gotman (2011). Lembraremos também com Mauss (1974), a hospitalidade como dádiva e as leis que daí decorrem.

Vamos tratar dos três momentos da hospitalidade. Em seguida, trataremos das leis não escritas, sua aplicação ao campo do turismo e, finalmente, tentaremos extrair dos nossos autores o que se supõe aqui sejam as leis da hospitalidade.

\section{HOSPITALIDADE E URBANIDADE}

O demógrafo Hervé le Bras (2005) diz que estamos diante de uma mudança das mesmas proporções que os caçadores/coletores do Paleolítico enfrentaram com a chegada da agricultura e da pecuária no Neolítico. Se nos dermos conta do que foi aquela passagem e se a intuição de Le Bras sobre o impacto da mudança estiver correta, no mínimo deve-se parar para pensar. Uma mudança de porte está acontecendo ou vai acontecer.

Foi na passagem do Paleolítico para o Neolítico que o ser humano sedentarizou-se (Léroi-Gourhan, 1966), para cuidar e proteger sua lavoura, seu gado ao invés da vida errante de antes, sempre dependendo das necessidades alimentares. Uma decisão tão simples e de consequências tão irreversíveis! As referências mais antigas do pensamento ocidental sobre o impacto dessa mudança encontram-se, sob forma metafórica, na Mitologia Grega e no Gêneses bíblico.

Como essas fontes entenderam a mudança? Para a Bíblia, a mudança significou ao homem a expulsão do Paraíso; para a Mitologia Grega o advento das misérias humanas. Na Bíblia, o casal original tinha ousado experimentar o fruto da árvore do conhecimento e foi punido com a expulsão do Éden onde vivia. Fora do paraíso, ele não pode mais viver das benesses da natureza. Passou a ter a obrigação de comer o pão com o suor de seu rosto. Surge o trabalho, entendido como um conjunto de tarefas diárias a cumprir. Para defender sua lavoura e seu gado, precisava-se de uma casa fixa bem como de braços e, em consequência, de mulheres. Estas, que antes tinham os filhos ao acaso e com largo intervalo de amamentação, agora tornam-se procriadeiras. Mais: perdem o protagonismo de antes, em que eram garantidoras das tarefas mais importantes da família - alimentar, procriar, cuidar da cria - e agora, em nome da necessidade de mais braços para o trabalho, foram obrigadas a aceitar a poligamia dos homens (Engels, 2002). Com a acumulação de bens, o patriarcado substitui o matriarcado. A guerra substitui a caça como oportunidade de descarga da testosterona de adolescentes e jovens do sexo masculino.

A Mitologia Grega não é menos cruel na análise das implicações da mudança. O semideus Prometeu roubou o fogo do Olimpo e o trouxe ao mundo para ensinar a trabalhar. Impossibilitado de reverter o estrago, Zeus o condena a ficar acorrentado numa rocha em que os abutres vinham durante o dia comer o seu fígado que se regenerava durante a noite. Maior metáfora para o suplício do trabalho, nela também está inscrita na tragédia de Síssifo, condenado a durante o dia carregar uma rocha ao topo de um monte e deixá-la rolar para recomeçar tudo no dia seguinte. Ou, sempre: em consequência da ousadia de Prometeu, acontece a desgraça de Pandora que abriu a caixa fatídica de onde saíram o trabalho, a doença, a loucura, a velhice, a mentira, a cobiça, a paixão.

A introdução do trabalho no Neolítico desencadeou a chegada do patriarcado, da luta de classes, da escravidão dos mais fracos, da acumulação de bens e de milícias para proteger esses bens, de hordas que se deslocavam dispostas a sobreviver da carnificina que realizavam. O fratricídio bíblico (ELIADE, 2010) é emblemático da mudança: o primeiro agricultor, Caim, matou o primeiro pastor, e fundou a primeira cidade. Para regular o mundo de funcionamento ainda desconhecido, a humanidade teve de aprender ao longo de 5 milênios a criar regras de convivência e grupos maiores de pessoas puderam ser reunidas, donde as instituições necessárias ao seu funcionamento: cidades e os exércitos para protegê-las, um clero para suportá-las ideologicamente, a monarquia para governá-las, uma linguagem escrita para registrar fatos e valores, e, assim, tem início a História. 
Benveniste (1975), estudando o vocabulário das instituições indoeuropéias, coloca a hospitalidade como uma dessas instituições e a define semanticamente como a fórmula usada como estratégia diante do enigma: como se portar diante do desconhecido, estranho ou estrangeiro? Será ele um amigo, que se transformará em hospes ou será o inimigo pura e simplesmente, o hostis? Derrida (1999) registrou essa tensão ao dizer que o termo hospitalidade na verdade deveria mudar para hostipitalidade, ou seja, exatamente o enigma que nos propõe todo estranho/estrangeiro ou desconhecido.

Isso muda, no advento da Modernidade, com as cidades adquirindo protagonismo em relação ao campo. Embora tendo surgido ainda no Neolítico, somente então, com a revolução industrial, as cidades tornaramse sustentáveis, colocando-se como o espaço preferido de agrupamento humano. Mas as regras de convivência na cidade tinham de ser diferentes. Havia necessidade de um código que aproximasse estranhos, mais restrito do que o codificado pela hospitalidade.

Pode-se dizer que se tratava, então, de um processo civilizador (Elias,1994) da adaptação de migrantes da zona rural para as diferentes posturas exigidas pela cidade, que envolvia protocolos dos mais diferentes tipos: como se portar à mesa, como se vestir, como conversar, como comer, que hábitos evitar, etc. Civilização é sinônimo de repressão, de formalismo. Assim nasce a chamada etiqueta moderna. Aliás, etiqueta é termo hoje depreciativo por designar comportamentos formais e inócuos além de ultrapassados.

Como argutamente observou Simmel (1973; 2004), na cidade os indivíduos estão sempre na defesa diante do desconhecido com que cruzam. Adotam um relacionamento mais superficial, mantêm uma reserva, ou mesmo uma repulsão, que, se partilhada, pode degenerar em conflito. 0 aumento de interações cria uma hierarquização de simpatias, desinteresses e de aversões. 0 ritual estabelecido repousa sobre uma lógica: ficar à vontade mas sem constranger o outro; ser discreto; polidez mas com distanciamento; não falar com estranhos; não expor sua intimidade, não ser motivo de preocupação a outros.

Este conjunto de regras é aqui chamado de urbanidade, a forma que a hospitalidade assumiu no advento da cidade moderna. Urbanidade, etiqueta, civilidade são termos quase semelhantes examinados nessa perspectiva. É uma forma de se relacionar socialmente que se assenta em atitudes e posturas assépticas, despidas de calor humano.

Dessa forma, surge uma hospitalidade encenada, em especial no acolhimento ao grande público. Criam-se protocolos para o bom atendimento, traduzido em gestos, frases, posturas e no hoje abominado riso comercial.

Essa fórmula da urbanidade foi bem sucedida enquanto mesmo nas grandes cidades conseguia-se manter um campo de relações primárias, as marcadas pela maior intimidade, sempre pessoais na família, no círculo de parentes, vizinhos e amigos, que ajudavam a suportar a impessoalidade no cotidiano.

Na passagem da sociedade sedentária para a da mobilidade, que mudanças são as temidas por Hervé Le Bras no emprego, na escola, na família? Onde está a referência que substituirá a casa, a vizinhança, o entorno acolhedor, a empresa onde sempre se trabalhou, a rede de amigos de toda uma existência que nos amparava na inospitalidade do mundo? Onde moramos mesmo? Numa casa, num apartamento, num quarto de hotel, na cabine de um avião? As famílias nucleares tendem a desaparecer e surgem as baseadas em arranjos diferentes entre parceiros e filhos. Os vizinhos hoje? São os colegas de trabalho, sempre provisórios a preencher grupos e grupos de whatsapp.

\section{DA URBANIDADE À HOSPITABILIDADE}

Entenda-se bem o ponto de partida central desta reflexão: se as pessoas de certa forma se adaptaram ao primeiro surto de vida coletiva na Modernidade, com um conceito de urbanidade que valorizava o trato cordial, agora parece que a exigência é maior. De um lado, o contato polido e frio cansa. De outro, a dinâmica da cidade moderna e a crescente mobilidade destroem nossos lugares, assim chamados antropologicamente os espaços de intimidade, sobretudo a vizinhança. Em consequência, não há um cansaço com o tratamento formal da urbanidade, uma aspiração por relacionamentos mais autênticos, mais baseados na convivialidade?

Mesmo no comércio, a forma estandardizada de receber é hoje malvista. O riso comercial é cada vez menos aturado. Termos como fidelização, customização refletem a busca de um relacionamento mais pessoal com 
o cliente. Frases polidas são cada vez mais ridicularizadas pela suspeita de envolverem apenas um desejo de não envolvimento. 0 bem receber torna-se mesmo um diferencial de competitividade.

O que é então o bem receber que se busca? Qual é a melhor forma de receber bem? A palavra hospitalidade torna-se inadequada porque abrange todas as formas de receber/ser recebido. Ademais, designa também um campo de negócios. Por isso, os britânicos cunharam o termo hospitabilidade, a capacidade, a habilidade. Como diz Lashley:

A hospitalidade pode ser entendida como uma característica fundamental, onipresente na vida humana e a hospitabilidade indicaria a disposição das pessoas de serem genuinamente hospitaleiras, sem qualquer expectativa de recompensa ou de reciprocidade (2015, p. 82).

Lashley estabeleceu também o que se pode chamar de degraus da hospitalidade: o primeiro, o mais elementar e negativo e o último o mais positivo. Segundo ele, "existem desde ocasiões em que a hospitalidade é oferecida com a expectativa de se obter lucro, até situações em que a hospitalidade é oferecida meramente pela alegria e pelo prazer de acolher" (2015, p. 82). Temos assim, dispostas num eixo, a hospitalidade desde a forma mais corrompida por interesses exteriores à mais altruísta assim explicadas pelo autor:

- hospitalidade de motivação oculta, que envolve um interesse qualquer;

- hospitalidade restritiva, típica de antigos reis, motivada pelo medo em relação ao estranho, como se diz no provérbio atual: “mantenha seus amigos perto e os inimigos mais perto ainda;

- hospitalidade comercial, que envolve uma transação financeira, podendo ou não tratar-se da verdadeira hospitalidade: se vender hospitalidade é um problema, há pessoas que investem em negócios que envolvem a verdadeira hospitalidade;

- hospitalidade recíproca, oferecida dentro de contextos em que os anfitriões se tornam hóspedes e os hóspedes se tornam anfitriões, continuamente.

- hospitalidade redistributiva, caritativa, oferecida sem expectativa imediata de retorno, reembolso ou reciprocidade.

- hospitalidade altruísta - a oferta da hospitalidade como um ato de generosidade e de benevolência ou de dar prazer aos outros.

Uma crítica possível a esse esquema de Lashley, de resto bem explicado e fundamentado, é que envolve apenas o anfitrião, deixando de lado o hóspede. O resultado de uma cena é consequência do desempenho desses dois atores. E aqui resulta claro que, diferentemente das leis do direito positivo, cuja violação é sancionada com prisão e multas, no caso das leis não escritas da hospitalidade, sua inobservância leva à inospitalidade e à hostilidade, como ilustrado no quadro abaixo:

Figura 1 - Hospitalidade da hostilidade à hospitalidade

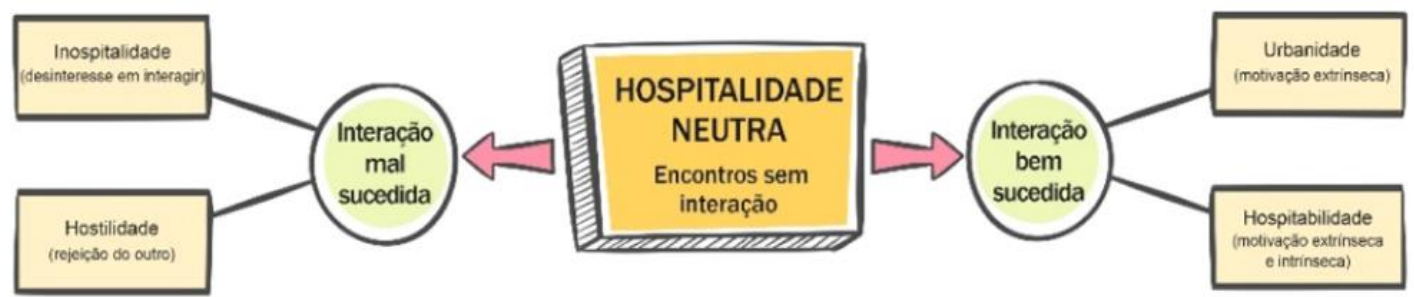

Fonte: Camargo (2020).

Esse quadro sugere que o encontro entre alguém que recebe e alguém que é recebido pode acontecer com maior, menor e mesmo nenhuma interação.

\section{- hospitalidade neutra}

Diz respeito à maneira mais corrente de (não) receber e de (não) ser recebido mormente nas metrópoles. $\mathrm{Na}$ azáfama do dia a dia, encontramos nas ruas, nos meios de transporte, nas lojas, uma infinidade de pessoas com quem não trocamos gestos, olhares, palavras. Olhar sem ver, falar sem dizer nada, perguntar 
e responder mecanicamente dão o tom de relações até mesmo impossíveis, como o ilustra a piada do caipira que veio a São Paulo e não conseguiu sair de uma esquina movimentada por querer dar um bom dia a todos que passavam. A hospitalidade neutra marca o indivíduo isolado na multidão.

Mas quando alguma relação se estabelece, a interação pode ser mal sucedida ou bem sucedida, a depender da disposição dos atores na cena. Se mal sucedida, a interação caminha para a inospitalidade e, a depender das circunstâncias, para a hostilidade.

\section{- inospitalidade}

Encontro em que, da parte de quem recebe ou de quem é recebido, não se reconhece o interlocutor ou ele é ignorado pura e simplesmente. Ignorar o outro não é um ato violento em si, mas demonstra inamistosidade, desejo de não estabelecer contato com o outro ou, pior, traz uma agenda secreta. Portanto, abre caminho para o último degrau negativo.

\section{- hostilidade}

É o resultado de ações agressivas que levam ao esgarçamento das relações humanas. A hostilidade não é resultado apenas do descumprimento das leis da hospitalidade. Ela tem inúmeras fontes. Mas não há dúvidas de que as mazelas registradas nos encontros interpessoais constituem grande parte do universo da hostilidade humana.

Mas pode ser bem sucedida e do lado virtuoso, o resultado pode aparecer sob dupla forma, encenada (urbanidade) e genuína (hospitabilidade).

\section{- urbanidade}

É o encontro agradável e que deixa a impressão de um exercício profissional eficiente. Engloba os contatos em que a boa interação positiva acontece mas com interesse explícito de ambas as partes. É a regra no comércio e em todas as áreas presenciais e virtuais de atendimento ao público, que Anne Gotman chama de hospitalidade encenada (2008). Como lembrou Lashley acima, a hospitalidade exercida profissionalmente pode ser apenas utilitária mas às vezes embute também o gosto de ser hospitaleiro ou de criar um ambiente mais propício ao contato humano. A hospitalidade genuína (descrita a seguir) transborda da encenação e boa parte desses atores também pode ser colocada no patamar superior, da hospitabilidade.

\section{- hospitabilidade}

A hospitabilidade genuína é o selo que marca o encontro entre pessoas que sabem e gostam de receber e de serem recebidos, que conhecem e praticam institivamente ou por aprendizado as leis da hospitalidade. Esses momentos são frequentes entre os voluntários de toda sorte, clérigos e até mesmo entre os profissionais do serviço. A hospitabilidade designa a hospitalidade genuína e marca os encontros mais memoráveis do cotidiano.

Não se quer aqui definir o perfil da pessoa com a habilidade hospitaleira. Mais propriamente do que dizer que uma pessoa é hospitaleira, vale dizer que seus contatos tendem a ser hospitaleiros. A hospitalidade é dividida em cenas, como num teatro, muitas vezes estanques. Podemos agir com hospitabilidade numa cena em que recebemos ou somos recebidos e na cena seguinte sermos hostis, mas nunca é demais reforçar a existência de um aspecto essencial da personalidade do indivíduo que gosta de ser hospitaleiro, a prevalência do gosto de servir. Se, em regra, as pessoas gostam de serem servidas, há - supõe-se, caso de minoria - pessoas que, ao contrário, gostam de servir.

Como confirmou Guimarães (2019), a hospitabilidade é fruto de uma motivação intrínseca e extrínseca para o gosto de encontrar pessoas. Nesta categoria, as pessoas definem o gesto de servir como a sua vocação e um aspecto importante da sua personalidade. Os dotados de hospitabilidade são como aqueles personagens bastante representados na ficção que, ao serem confrontados entre o protocolo, a atitude mais cômoda, e essência de suas missões, optam por este caminho mais difícil e arriscado. 


\section{LEIS NÃO ESCRITAS}

Quando se fala de leis, as únicas referências não são os códigos e manuais de direito. Há outras formas de lei e, entre estas, incluem-se as que dizem respeito à hospitalidade. Receber alguém em seu espaço, seja em casa, seja na rua ao ser abordado, seja no local de trabalho na relação interpessoal com colegas, chefes e clientes, seja respondendo e-mails, ou, inversamente, adentrar o espaço de outro nas mesmas circunstâncias são rituais controlados por regras severas, autênticas leis.

A hospitabilidade sempre escondeu um paradoxo. É gratuita, ou seja, despida de interesse que não o de bem receber/ser bem recebido. Não exige, mas supõe a retribuição e a compensação da parte do outro. Ou seja: é livre e obrigatória ao mesmo tempo. Ou seja ainda: você é livre para obedecer mas caso não obedeça será punido com a hostilidade.

São leis não escritas que, da mesma forma do que as que Marcel Mauss (1974) atribuiu à dádiva: não fazem parte do direito positivo e sim de um direito ancestral que cristalizou-se ao longo dos tempos como uma ética. De onde vêm tais leis? Sob qual argumento de autoridade elas são formuladas? Falando exatamente sobre a natureza das leis da hospitalidade, escreve Innerarity (2001, p.15): “(existe) uma sabedoria sem argumentos, nas práticas da vida humana, em seus costumes e instituições (o que nos leva a) saber o que é correto antes de conhecer a regra da qual deriva".

Marcel Mauss (1974), relendo pesquisas de antropólogos de sua época, formulou o conceito de troca (toda hospitalidade é uma troca) baseado na fórmula que se tornou o mantra dos antropólogos: dar-receberretribuir. Este sistema, ancestral, convive hoje com o sistema mais conhecido da troca comercial. No caso da dádiva, a troca é pessoal, infinita, cada protagonista sendo sucessivamente preso à troca pela dádiva que recebeu, alternando as posições de doador e receptor. Já a troca comercial tem lógica diferente: um contrato simétrico entre iguais, impessoal, finito.

Julian Pitt-Rivers fala da hospitalidade como uma ambivalência pois "não elimina totalmente o conflito, mas coloca-o em suspenso e proíbe a sua expressão" (2012, p. 513). Entende-se, pois, que resolver as raízes dos problemas que levam à hostilidade é missão que sobrepassa o instituto da hospitalidade. Não é este o sentido das expressões verbais rituais da hospitalidade? Não é este o sentido do "bom dia", "boa tarde" que dirigimos às pessoas ao chegar a um ambiente? As palavras não se referem à beleza do dia, mas tão somente ao desejo de dizer ao outro que tudo está bem e aguardar sua resposta nos mesmos termos para assegurar que o contato pode ser entabulado. Mas a cena hospitaleira é efêmera e a hospitalidade nela desenrolada só pode ser estudada como cena encadeada com as anteriores e as seguintes. Aliás, é nesta sinfonia do cotidiano em que se sucedem cenas de hospitabilidade, de inospitalidade e de hostilidade que as ficções literárias, dramatúrgicas e cinematográficas se estruturam.

Afinal, quais são as leis da hospitalidade? A primeira referência, talvez, deva ser literária, ao menos por ser a que ostenta o mesmo título deste artigo. Nela, o romancista Pierre Klossowski (1995) desnuda o ritual erótico da hospitalidade, com uma paleta cheia de ironia: se a hospitalidade é o desejo de fazer o hóspede feliz, nada mais natural do que permitir-lhe a hospitalidade total, o acesso a todas as delícias da casa, inclusive da bela anfitriã. Aliás, esse ritual fez parte de várias culturas (Gotman, 2009).

Mas não é na literatura e sim na filosofia que se encontram as maiores referências sobre esse dever. 0 primeiro a ser lembrado é Kant (1995) para quem a hospitalidade é um problema moral e não jurídico. É um dever e nada tem a ver com piedade ou compaixão. Tudo se passa como se, para Kant, à semelhança de outros enunciados de imperativo categórico, tratar bem o hóspede seja a consciência de que todos somos hóspedes e essa é uma lei de que cada um deve gostar a ponto de torná-la universal.

Essa abordagem pioneira de Kant expandiu-se na segunda metade do século XX. Dos estudos existentes, quatro leis podem ser arroladas:

\section{Primeira: INCONDICIONALIDADE: o pedido de hospitalidade deve ser aceito}

Como nota Perez (2007) se, para Kant, a obrigação de receber outrem tem limites, para Levinas, que Derrida cultuava como mestre, não há limite para a abertura diante do outro. A este não se deve perguntar o nome. Segundo Levinas (1988), é o outro que nos constitui e que por isso se é responsável por ele, mesmo que não se saiba quem é o outro e não importa quais sejam suas características positivas ou negativas. Ele vai 
além do direito e fala de uma "ética da responsabilidade", que se corresponde com a questão dos estrangeiros sem documentos. A hospitalidade é um problema ético e não jurídico.

$\mathrm{Na}$ cola de Levinas, Jacques Derrida insiste na importância do outro. Para ele, a hospitalidade é incondicional e ele estabelece a extensão e os limites dessa incondicionalidade. De início, mostra como a noção de tolerância é mais do que uma imitação tacanha da hospitalidade. Como declarou em entrevista (Borradori, 2004):

\begin{abstract}
A hospitalidade é o oposto da tolerância. Esta diz: eu te concedo o direito de continuar vivendo. Já a hospitalidade é incondicional. Não pode realizar-se na frase: eu o convido, eu lhe dou as boas-vindas ao meu lar, sob a condição de que você se adapte às leis e normas do meu território, de acordo com a minha linguagem, tradição, memória, etc. (ao contrário) abre-se ou está aberta previamente para alguém que não é esperado nem convidado, um recém-chegado não identificado e imprevisível, em suma, totalmente outro (2004, p.138).
\end{abstract}

Mas Derrida, com esta lei, pensava mais na hospitalidade entre as nações, mostrando-se contra todas as normas restritivas de circulação de pessoas, exatamente onde a violação desta lei tem consequências mais perversas, como o revela o caso das ondas atuais de refugiados. No mesmo diapasão, devem ainda ser lembrados os nomes de René Scherer (1993), que buscou na história e na filosofia da história as bases de um direito cosmopolítico respeitador da hospitalidade, atribuindo a esta a condição de hominização, de definição do atributo de humanidade que caracteriza o homo sapiens e que, portanto, deve ser universal. Ainda no plano da filosofia, há que se mencionar Louis Massignon (1987) e suas reflexões sobre a hospitalidade como um dever sagrado e Edmond Jabés (1991) que fala da hospitalidade como uma "boa nova" - a semelhança semântica com a palavra evangelho (eu-angelos) é intencional - o arco-íris que simboliza o pacto pela qualidade de anfitrião/hóspede a ser transmitido de geração e geração.

A lei da incondicionalidade é a contribuição seminal de Derrida para os estudos de hospitalidade. Ao longo da aventura humana (e quem sabe desde o seu início) colocou-se a ideia de que recusar o acolhimento a outrem é uma violação do caráter humano da espécie, seja ele quem for, venha de onde venha, quaisquer sejam as suas caraterísticas de gênero, idade, etnia, e mesmo suas intenções.

E os limites dessa incondicionalidade? Em primeiro lugar, Derrida reconhece que esta não cabe no estatuto das leis do direito positivo. Como lembra Perez (2007, p. 25) "não poderia ser resolvida nos termos da aplicação de uma lei moral ou jurídica”. Mais: como declarou em outra entrevista:

Uma comunidade cultural ou linguística, uma família, uma nação, não podem deixar de suspender ou mesmo de trair este princípio da hospitalidade incondicional, para proteger sua casa, o próprio e a propriedade contra a chegada ilimitada do outro, mas também para propiciar um acolhimento efetivo. (Derrida, 1997, s/i - tradução livre)

Quais as formas de violação dessas leis? 0 anfitrião pode ser desinteressado, alguém que não se interessa nem em saber o nome do hóspede. Pode ser distímico e só pensar na despesa que está tendo. 0 hóspede também pode manifestar a mesma síndrome e nem se ocupar em saber quem é seu anfitrião.

Além dos limites à incondicionalidade de que fala o próprio Derrida, deve-se mencionar o problema da incondicionalidade na hospitalidade virtual. Não é o caso nem de mencionar os SPAMs, comunicação de massa e que não se dirige especificamente a ninguém e que, portanto, não espera de todos uma resposta, mas o volume das solicitações pessoais aumentou consideravelmente. Com a tecnologia passando do telefone ao e-mail e às redes sociais em geral, o volume de interações diárias aumentou significativamente. O que significa a incondicionalidade nesta situação?

Resposta: exatamente o mesmo que acontece no plano presencial. Não responder a um e-mail pessoal de alguém que nos pede algum tipo de retorno tem o mesmo registro da negativa presencial. Qual é a pena? Como esta lei é sancionada? Tanto no plano virtual como presencial, supõe-se que o indivíduo que acolhe, o anfitrião, tenha a exata noção de que algo ocorre quando ele não diz "não" a outrem ou quando ele não se cerca das devidas garantias de que tal atitude não será entendida como transgressão a esta lei. Isto vale para o estranho que nos aborda na rua e nem consideramos seu pedido, seja por motivo de pressa, de medo ou de preconceito. Vale para o indivíduo que nos aborda altas horas da noite em nossa casa ou ao indivíduo que procura um hotel e ouve que só pode ficar se pagar o preço estabelecido, etc. Abre caminho para a hostilidade.

Se a sanção coloca limites, os estímulos para a prática da incondicionalidade são poderosos, sobretudo das religiões. E se o desconhecido for um anjo ou um deus? Como escreve Richard Martin na apresentação da Odisséia de Homero (2014): 
Não é de surpreender que, numa cultura arcaica, pré-alfabetizada, onde não havia instituições internacionais ou normas reconhecidas, o comportamento correto em relação a estranhos fosse considerado obrigação sagrada.(...) Essa era, com efeito, a única maneira pela qual indivíduos podiam sobreviver além dos limites de sua comunidade local. Zeus tinha um título especial, Xenios, para denotar seu papel como protetor de estrangeiros. Qualquer infração era, pois, uma ofensa contra o deus supremo.

A Bíblia conta que Abrahão, depois de sacrificar suas primícias para bem receber três desconhecidos, ouve deles ao final que eram anjos e que, pela hospitalidade recebida, premiaram-no com a gravidez tardia de sua mulher Sara, já com 90 anos. Na mesma viagem, em Sodoma, os anjos tornam-se hóspedes do único homem virtuoso, Lot, sobrinho de Abrahão e o recompensaram com a fuga de Sodoma antes da destruição da cidade. Do mesmo modo, Zeus e Hermes, viajando pela Frígia na história do poeta latino Ovídio nas Metamorfoses, são recebidos apenas por um casal de velhos, Filemón e Baucis. Gratos, os dois viajantes se apresentam e se prontificam a atender um pedido dos seus anfitriões que foi bastante singelo: queriam morrer e ser enterrados juntos. A vingança à cidade que não os aceitou foi cruel: a água de um lago a devorou. Assim, aquele que recebe o desconhecido acolhe um ser divino e é largamente recompensado.

Mais do que um exemplo de hospitabilidade, o mito grego fala algo que é usual nas mais diferentes sociedades. A hospitabilidade deve ser incentivada e é uma virtude porque rara, como ocorre com as virtudes em geral (Camargo, 2015). A incondicionalidade vale para o anfitrião e para o hóspede, embora o próprio Derrida tivesse em mente basicamente o anfitrião. As demais leis trazem com mais clareza as obrigações do hóspede.

\section{Segunda: RECIPROCIDADE - anfitrião e hóspede devem honrar-se mutuamente}

Um das contribuições mais importantes ao estudo da hospitalidade vem da pesquisa de Julian Pitt-Rivers (2012) sobre os códigos da nobreza na Andaluzia. Segundo ele, naquela sociedade a esfera privada abrangia uma rede de sociabilidade infinitamente mais extensa de que nas sociedades fundadas sobre o instituto do salário. As relações sociais eram o principal caldo de cultura da reputação e da honra do indivíduo. Lá encontrou bem no centro dessas relações determinado código que ele denominou de lei da hospitalidade. Afinal, uma sociedade estruturada na honra como critério nas relações sociais é um campo suculento para observar a hospitalidade em vigor tanto num plano ético como estético. Se o aspecto ético da hospitalidade é bastante estudado, o aspecto estético o é menos. Mas a honra de que falavam os observados de Pitt-Rivers era colocada no mesmo plano da elegância. 0 gesto intrinsecamente hospitaleiro é um gesto elegante, que denota a nobreza que não vem do sangue mas de um profundo senso de respeito ao outro, lembrando o princípio grego ético e estético da kalokagathia, o bom e o belo reunidos.

Anfitrião e hóspede devem honrar-se mutuamente. Como traduzir esta lei hoje? 0 anfitrião honra o hóspede colocando a casa à sua disposição, franqueando-Ihe a senha de wi-fi, cumulando-o de pequenas lembranças e dádivas, sobretudo alimentos e bebidas, interagindo com prazer sobretudo na conversação. 0 hóspede homenageia o anfitrião aceitando seu convite, trazendo-lhe presentes e lembranças, trazendo alegria, honrando-o com palavras.

Essa lei pode ser transgredida tanto pelo excesso como pela falta. Pelo excesso, o anfitrião transforma-se em sequestrador. 0 anfitrião se vale da contra-obrigação do hóspede de aceitar todas as suas dádivas e, assim, intencionalmente ou não, submete-o à sensação de que está aprisionado. Esse sequestro pode ser produto de uma certa ingenuidade do anfitrião que, sem querer, afoga o hóspede nas suas gentilezas, mas pode ser também produto de uma agenda secreta, como no caso do conto de fadas em que Joãozinho e Maria são recebidos pela bruxa má que os aprisiona para engordá-los e depois devorá-los.

Diga-se de passagem que, sob diversas formas, às vezes mais às vezes menos claras, esta transgressão ainda se mantém em todas essas formas no nosso cotidiano. Afinal, quem de nós que, como hóspedes, já não se sentiu prisioneiro de uma cena, sendo obrigado a vivê-la contra a vontade até o fim?

O hóspede transgride pelo excesso quando procura se sobrepor ao anfitrião ou ao homenageado do encontro ou quando de alguma forma destaca o valor material do mimo oferecido aos anfitriões.

A transgressão pela falta ocorre quando o anfitrião deixa claro que não recebe pessoas e sim currículos. Sentir-se desprestigiado por um anfitrião por não ostentar o estatuto desejado pode ter significados variados: se ocorre quando um anfitrião generoso decide que quer receber muita gente e cada visitante a mais é um ponto a mais em sua autoestima, sabe-se que se está ali apenas como figuração. Desfruta-se da 
cena e de suas primícias e, ao final, fica-se apenas um sentimento de gratidão. Mas quando o anfitrião não faz questão de exibir a postura ideal na cena (de satisfação pela presença daquele hóspede especificamente) ou se simplesmente ignora seu hóspede, é claro que o sentimento final deixa de ser o da gratidão. 0 "obrigado" ao final é apenas uma formalidade. 0 hóspede transgride pela falta, esquecendo, sem uma boa justificativa, uma "lembrancinha" aos anfitriões ou não os fazendo sentir a gratidão pelo convite.

Em resumo: obedecer a esta lei implica na busca de uma cena em que resulte, para o hóspede, numa sensação equilibrada quanto ao desvelo do anfitrião para com ele: nem excessivo a ponto de constranger, nem omisso a ponto de fazê-lo sentir-se abandonado. Para o anfitrião, a sensação de ter oferecido uma cena agradável aos hóspedes. Por isso, a maior homenagem do hóspede é a demonstração da satisfação em ali estar e quem sabe ser um protagonista daquilo que Lugosi (2008) chama de meta-hospitalidade, a capacidade de viver um momento mesmo que fugaz em que o limiar que separa anfitrião-hóspede se dilui e todos explodem num jubilo coletivo.

O anfitrião também pode protagonizar a meta-hospitalidade? Sim, mas, ao que parece, esta nunca é tão visível como a proporcionada pelo hóspede. 0 bar de Budapest analisado por Lugosi e as cenas com que se depara em certas festas o demonstra.

É claro que aqui não cabe analisar, apenas lembrar a figura do hóspede movido a cachê, tão em voga atualmente. Os promoters (produtores e animadores de festas) sabem que uma das formas de valorizar uma recepção, uma festa é ter convivas que representem motivação adicional para os convidados. Daí ao surgimento do hóspede pago mediante cachê para abrilhantar uma festa torna-se corriqueiro nas altas rodas.

As demais leis já significam a imbricação de dois institutos: da hospitalidade e da dádiva. Como diz Godbout (1997, p.35), "hospitalidade não diz respeito apenas à dádiva, mas a questão é se podemos falar de hospitalidade sem a dimensão da dádiva".

\section{Terceira - ASSIMETRIA - o hóspede deve respeitar o direito do anfitrião ao espaço}

Pitt-Rivers foi o primeiro a lembrar o hóspede como coprotagonista e a lembrar a assimetria que permeia a cena hospitaleira: o hóspede está sujeito às regras do anfitrião. A mesma lei está presente na dádiva. A hospitalidade, como toda dádiva é assimétrica. Aquele que recebe aceita a posição superior do doador, inclusive como dono do espaço. É natural que o anfitrião pronuncie a frase ritual "faça de conta que a casa é sua", mas não cabe ao hóspede entendê-la senão como uma cortesia.

A soberania do anfitrião e a assimetria resultante são refletidas ainda pela territorialização do hóspede e estabelecimento das fronteiras em que ele pode se locomover. Há uma barreira, mesmo invisível, situada entre o espaço do anfitrião e o alocado ao hóspede. Toda e qualquer iniciativa do hóspede, inclusive o uso de qualquer aparato da casa, torna necessária uma consulta ao anfitrião. A territorialização do hóspede também acontece nos casos do turista e do imigrante ou do refugiado. Ao turista, quando apenas se quer mostrar o que pode ser visto. Transposto para a lei de Estados, a territorialização é imposta a estrangeiros indesejáveis.

Segundo Gotman (2011), a lógica da assimetria se concretiza de várias maneiras. Primeiro, pelas condições de entrada impostas ao recém-chegado cujas qualidades são pesadas e sobrepesadas, ainda mais quando ele é desconhecido. Se um estranho aparece inesperadamente no limiar da casa, ele será submetido a um exame probatório, a uma fase de observação durante a qual o anfitrião avaliará sua elegibilidade para a hospitalidade. Uma simples olhada pode bastar para ler o seu perfil e abrir a porta ou fechá-la.

O hóspede deve adotar todas as cautelas prévias e, mesmo convidado ou autorizado a entrar, deve titubear na soleira (material ou imaterial da cena) e aguardar um segundo convite para entrar e, em seguida, postarse no local da cena indicado pelo anfitrião e pedir licença para toda e qualquer movimentação pelo espaço ou para usar de qualquer serviço da casa. 0 "por favor" torna-se central no ritual.

Se a cena hospitaleira está povoada de armadilhas é nos meandros dessa lei que se escondem as maiores. Qualquer sobrepasso do anfitrião pode ser novamente chamado de sequestro. Qualquer sobrepasso do hóspede pode ser chamado de intrusão; 
A figura do intruso pode ser entendida como daquele que invade o espaço do anfitrião tanto no sentido físico como figurado. O indivíduo vulgarmente chamado de espaçoso é o que viola os limites do espaço físico instituídos pelo anfitrião. Mas pode ser também o que busca visibilidade acima daquela que lhe é conferida na cena ou de empanar o brilho de algum homenageado, como a querer tomar-lhe o lugar, etc. A intrusão é a forma de transgressão mais temida pelo anfitrião, o que o obriga a adotar outra função, a de vigiar o hóspede e adotar todas as estratégias para tal.

\section{Quarta: COMPENSAÇÃO: 0 hóspede deve receber e retribuir à hospitalidade}

Como lembra Gotman, além da assimetria, ainda existe para o hóspede a necessidade da compensação, também "terra minada, fonte de mal-entendidos inúmeros e rancores acumulados" (2011, p.20), especialmente importante quando se hospeda alguém.

A primeira compensação esperada do hóspede é que ele aceite o convite e as dádivas do anfitrião. Como dizer não sem que o gesto seja interpretado como inimizade? Aceitando, ele estará dando um sim a uma amizade ou a uma promessa de amizade futura ou estará sepultando mágoas e conflitos passados.

A segunda compensação é comparecer. Quem ainda não ficou com um jantar pronto esperando por hóspedes que não vieram ou, pior, esqueceram-se do "compromisso"? Que palavras usar para justificar a falta? Comparecer é aceitar integralmente a dádiva. Mais: é um sinal de cessar fogo. Fugir dessa regra exige uma engenharia de ação. No romance de Alexandre Dumas, Edmond Dantés, o Conde de Monte Cristo, salvou a vida do filho de seu inimigo, Fernando, o Conde de Morcerf (que havia roubado sua noiva Mercedes), e até aceitou o convite para visitar sua casa, usando de um artifício. Comparecendo, selou a amizade com o rapaz, mas ao recusar até mesmo um copo de água por problemas digestivos, mantinha, conforme costumes da época, o seu projeto de vingança intacto.

A terceira forma é comportar-se à altura. A “lembrancinha” à dona da casa - ela sempre dirá "que gentileza! não precisava!", mas o hóspede sabe que precisava, sim! - as roupas e adereços que permitem às mulheres todo gênero de comentários favoráveis ou desfavoráveis, todas são formas adicionais de retribuição, sem falar da menos explícita (embora hoje abundem as festas e reuniões em que cada convidado traz uma comida e/ou bebida) que reside na participação, ainda que pequena, na economia do evento.

Se todas as decisões nesse âmbito são delicadas, a mais difícil, ainda segundo Anne Gotman, é a que delimita a generosidade de ambos os lados. O exercício da hospitalidade "exige do anfitrião um sacrifício de tempo e de dinheiro, sem deixar de mencionar a quebra da cômoda rotina do cotidiano da qual o hóspede é mais ou menos convidado a participar" (2011, p.22). O pior é que nada disso pode ser explicitado e cabe ao hóspede literalmente adivinhar que tipo de compensação oferecer. Esta poderá ser material ou simbólica. O hóspede competente para animar uma conversa ou uma festa torna-se um hóspede permanente e, mesmo sem uma dadiva adicional, é sempre lembrado.

Já o hóspede contumaz em nada retribuir logo será tachado de parasita. Em caso de hospedagem, se se limitar a comportar-se como um estranho será imediatamente criticado por acreditar-se num hotel, sem qualquer obrigação, até de pagar o custo da hospitalidade.

A dádiva material e a retribuição material são outras armadilhas. A primeira tem a ver com exageros, tanto pela exiguidade como pelo vulto. Nunca devem ser exageradas, como lembram as palavras do filósofo maluco Quincas Borba respondendo ao desolado deputado Brás Cubas, no romance de Machado de Assis. Brás Cubas falava da ingratidão de seu cunhado Cotrim que, reclamando das dificuldades financeiras, recebeu uma ajuda fantástica na forma de um contrato milionário com o Governo e que, depois, o tinha renegado publicamente. Como disse o filósofo, para o doador há no início o sentimento de uma boa ação, e dedutivamente a consciência de sua capacidade de boas ações; em seguida, há o sentimento de superioridade, inclusive do ponto de vista material. Já para o beneficiado, o agradecimento inicial será proporcional à dádiva recebida e esta inversamente proporcional ao alcance da memória do beneficiado. Quanto maior a dádiva, maiores serão o alívio e a gratidão iniciais mas mais rápida a dádiva tende a ser esquecida e o agraciado, na impossibilidade de retribuir à altura, poderá até mesmo voltar-se contra o doador.

Em segundo lugar, como lembra Pierre Bourdieu (1996), a retribuição nunca deve ser imediata sob pena de anular o efeito da dádiva recebida. Para isso, todas as línguas têm um arsenal de fórmulas para prometer 
e adiar a retribuição. Mas, como lembra Jean Lauand (2019), as línguas se diferenciam quanto ao alcance da retribuição. $\mathrm{Na}$ língua inglesa, to thank (agradecer) e to think (pensar) são, em sua origem, e não por acaso, a mesma palavra, do mesmo modo que, no alemão, zu danken (agradecer) é originariamente zu denken (pensar). Afinal, a pior ingratidão é não lembrar a dádiva recebida. Só está verdadeiramente agradecido quem pensa no favor que recebeu como tal.

Sempre seguindo Lauand, a formulação latina de gratidão, gratias ago, que se projetou no italiano, no castelhano (grazie, gracias) e no francês (merci) reconhece a importância da dádiva recebida, inclusive louva o doador. Mas apenas a fórmula da língua portuguesa aprofunda a noção de gratidão para falar de vínculo, de necessidade de retribuição. Obrigado nada mais é do que o resultado da elipse de uma frase mais longa: você me fez um favor e eu estou obrigado(a) a lhe retribuir.

Finalmente, há uma outra fonte de armadilhas nessa dança de dar, receber e retribuir. A hospitalidade mostra aqui suas faces ocultas: surge sob o signo da solidariedade mas é agonística, competitiva. Um quer vencer o outro. 0 potlach, tema de bastante interesse para os antropólogos - sobre tribos indígenas que competem pela capacidade de generosidade até a perda total dos bens de ambas as partes - não é a regra no cotidiano, mas é difícil não enxergar em toda cena hospitaleira a ideia de que alguém quer brilhar mais: pela generosidade, pelo requinte, pela retórica, pela elegância, pela beleza...ou mesmo pela ausência. Passar despercebido numa festa é o pior dos resultados ao hóspede.

Da mesma forma, uma sociologia da hospitalidade, ao adentrar o tema da conversação, chegará a outros temas esquecidos nessa disciplina. A fofoca e uma certa hipocrisia consubstanciada na chamada mentira piedosa são elementos constitutivos da relação interpessoal que servem de base à hospitalidade e estratégia de sobrevivência em meio à selva urbana.

É diferente receber/ser recebido em casa, na cidade ou no país? As leis até podem ser as mesmas mas há nuances que um estudo mais amplo poderia esclarecer. Aqui contemplamos o caso do turismo.

\section{O TURISMO E AS LEIS DA HOSPITALIDADE}

Gotman (2008) fala de turista e etnólogo como visitantes intrometidos, que têm na hospitalidade o seu ponto cego, pois não pedem permissão para invadir a intimidade de um grupo. No caso dos antropólogos, já há protocolos claros para o ingresso hospitaleiro dentro do grupo a ser estudado. No caso dos turistas, pode-se imaginar que a aduana aberta é a soleira da porta livre, quase um convite. Ademais, as cidades em seus sites não cansam de se vangloriar da hospitalidade local, o que é também um convite explícito de visita. Mas há sempre um déficit na relação, quase sempre do lado do anfitrião, o elo mais frágil da cadeia turística. De qualquer forma, turista e etnógrafo beneficiam do que Miguel (2016, p.527) chama de "direito de conhecer o mundo e de adquirir os instrumentos para pensar com a própria cabeça".

Hoje os benefícios econômicos do turismo o colocam na pauta das prioridades econômicas das nações, regiões e municípios. 0 turista é desejado, é o cliente-rei, e sua visita é estimulada. Mas a hospitalidade oferecida pelo receptivo turístico é, mais uma vez no dizer de Gotman (2008), encenada, uma metáfora da verdadeira hospitalidade, ou ainda, mero disfarce da sua natureza mercantil, o que não elimina as restrições mútuas.

Para o morador local, o turista endinheirado age, ainda com Gotman, como um conquistador em terra arrasada. Para o turista, o morador local é um explorador à espera do momento propício para assaltar a sua carteira. A expressão "para turistas" é emblemática da territorialização e da distinção pelos locais entre estabelecimentos para eles, autênticos e de preço justo, e para turistas, onde tudo é fake e caro.

Se os turistas podem ser hóspedes intrusos que pensar quando uma verdadeira horda repentinamente toma de assalto os pontos mais desfrutáveis das paisagens locais? É o overturismo e o movimento contrário da turismofobia (Camargo, 2019).

Tudo se passa como se o turista, a partir de um certo nível de visibilidade na paisagem local, deixasse de ser o cliente-rei e se transformasse num intruso, num violador da lei da assimetria e, em consequência, que faz urbanidade degenerar em hostilidade. Descobrir qual é esse nível talvez seja o grande desafio atual das ciências aplicadas ao turismo, implicando em ampliar o uso da noção de carga turística utilizada na proteção de ambientes físicos frágeis à totalidade do campo turístico. 
Mais eis que, em meio à revolução prometida por Hervé le Bras pela explosão da mobilidade humana, surge a pandemia do covid-19 bem como a previsão de novas epidemias semelhantes, cujo causador parece ser exatamente a mobilidade humana. De repente, a sedentarização se impôs novamente e toda mobilidade parece perigosa para a contaminação do vírus. Com isso, saem de cena o overturismo e a turismofobia e a questão passa a ser o futuro do turismo pós-pandemia.

Para onde caminhamos? As previsões sobre o futuro são complicadas, já que a natureza e os efeitos do vírus não são de todo conhecidos e o seu impacto no futuro ainda menos. Aqui interessa a questão: a revolução da mobilidade terá conhecido seu fim? Aparentemente não, pois, como disse Nietsche, as verdadeiras mudanças chegam nas patas da borboleta, "as palavras mais silenciosas trazem a tempestade" (1981, p.158) e não triunfalmente como se fala das revoluções políticas. A hipermobilidade é resultado de duzentos anos de evolução paulatina da tecnologia de transporte. Nesse período, cresceu de forma cada vez mais acelerada o desejo de mudança de paisagem, de ritmo e de estilo de vida que sempre estiveram subjacentes ao gosto da viagem. Assim, essa quase permanente excitação em busca do novo permitiu um cardápio repleto de alternativas onde tudo cabe e as recentes modas turísticas centradas em cenários celebrizados no cinema e no darkturismo são apenas alguns exemplos. É duvidoso imaginar que isso termine...

Pode-se imaginar que sobretudo num primeiro momento as pessoas se deslocarão menos, darão preferência ao turismo de proximidade mas é provável também que aos poucos os antigos hábitos sejam retomados. No Grand Tour, a viagem em si, com suas pausas, com os panoramas, era atrativo maior que o destino e os nobres ingleses queriam conhecer novas paisagens e novos povos. Hoje, a viagem desaparece com a velocidade dos meios de transporte e, seguindo Krippendorf (1989), as pessoas viajam porque não suportam a qualidade da sua vida cotidiana. 0 isolamento terá ensinado as pessoas a suportarem mais o tédio do cotidiano abandonando a vontade de viajar?

Por outro lado, as viagens virtuais deverão ter algum avanço, com a ajuda de simuladores, inteligência artificial, realidade aumentada. Não é difícil que o turismo virtual se consolide com grossas raízes nesse mercado, da mesma forma que o turismo local. Afinal, antes da pandemia, Krippendorf (1989) já recomendava viajar sempre para o mesmo lugar, de forma a criar laços com o local, e para cada vez mais perto.

Se, no plano da prática social, pouco se pode aventar, pode-se dizer que no mínimo é uma boa hora para o pensamento teórico sobre o turismo se redimir de seu pecado original que é a vinculação excessiva ao trade turístico a ponto de, até algum tempo atrás, nem serem incluídos nas cifras do turismo os que viajavam sem recurso ao trade e se hospedavam em casa de parentes e amigos. Uma rápida olhada mostra que a pauta do periódico mais prestigiado do setor, o Annals of tourism research, é quase inteiramente de interesse do mundo dos negócios. Algo de muito diferente se passou com os estudos do lazer que, desde Paul Lafargue (2000) e Thorstein Veblen (1965), ainda no século XIX, passando por Georges Friedman (1972), David Riesman (1975), Joffre Dumazedier (1995), sempre primaram pela crítica aos efeitos do mercado sobre o entretenimento, tais como alienação, desigualdade, conflito, etc.

O problema dos estudos do turismo é que cresceram à sombra do "trade" e por isso deram pouca atenção no início ao relacionamento entre visitantes e visitados. Mesmo a introdução da antropologia do turismo com o grupo de Smith (1970) não foi capaz de mudar o cenário. Suas teses coincidem com as do antigo Birô (hoje Organização) Internacional do Turismo Social, valorizadoras das leis da hospitalidade: aproveitamento integral do potencial educativo do turismo, relação harmoniosa entre visitantes e visitados e com a natureza. É difícil entender que estas teses sejam tão relegadas, banalizadas como turismo de pobres ou simplesmente turismo barato e mesmo desconhecidas.

Da mesma forma, também no turismo a fórmula da hospitalidade encenada parece esgotada. A atual valorização do turismo como experiência e não apenas como desfrute da paisagem marca o desejo dos turistas de desfrutar mais da viagem, incluindo maior integração com os moradores locais. Sem dúvida, a pausa da pandemia pode ser uma oportunidade para repensar e reestudar as bases do turismo nos planos local, regional, nacional e internacional. Resta esperar que a prática turística, respeitando as leis da hospitalidade, confirme um dia o ideal de paz entre povos e nações que sempre funcionou como uma espécie de meta a ser atingida. 


\section{CONSIDERAÇÕES FINAIS}

O estudo da hospitalidade em diferentes sociedades pode ser uma pista para o estudo de uma outra forma de meta-hospitalidade, diferente da concebida por Lugosi e já tratada aqui. Trata-se do acolhimento às teorias aplicadas à hospitalidade. É natural que em toda área do conhecimento haja teorias divergentes e até opostas mas que ao menos dialogam entre si. Não é o caso hoje quando se estuda hospitalidade. Há uma clivagem teórica que também é geográfica. Para anglo-saxões, sobretudo americanos, a hospitalidade era algo que existia no passado e que hoje foi substituída pela hotelaria e pelo receptivo turístico. Já para os francófonos, hotelaria e turismo nem mesmo são manifestações genuínas de hospitalidade. A equipe britânica de Lashley flexibilizou a concepção americana mais rígida, mas mesmo para eles a hospitalidade como dádiva nem sequer merece menção e na concepção francófona o tabu existe nos conceitos de comércio e consumo e, portanto, do próprio turismo. 0 Canal de Mancha parece uma distância ideológica intransponivel entre esses países. Espera-se que este texto tenha sido hospitaleiro a todas as teorias.

Seria a hospitabilidade uma qualidade inata de alguns privilegiados? Guimarães (2019) encontrou algumas pistas positivas, ainda que não conclusivas, sobre esta questão. Sua análise mostrou que as mulheres apresentam uma maior capacidade de serem hospitaleiras. Outro ponto é o fato de que pessoas mais lógicas e racionais ou mais organizadas e detalhistas tem menos tendência a serem hospitaleiras.

$\mathrm{Na}$ corrente que valoriza a ideia de substrato natural, de tipo biológico, no comportamento humano, que, aliás, não é majoritária, a tentação de aceitar esta hipótese é grande. Afinal, as ciências biológicas estão carregadas de termos quase simetricamente associados aos das ciências sociais e humanas. Hospitalidade, comensalidade, parasita têm como contrapartida hospitalismo (síndrome de indivíduos abandonados em hospitais), comensalismo (quando duas espécies se associam em benefício de uma mas sem prejuízo à outra), parasitismo (espécie que invade a outra para beneficiar-se em prejuízo desta). Numa outra linha, observa-se o vínculo formado entre bebê e mãe no aleitamento, a forma de domesticar animais (oferecendo comida) quase da mesma forma que a atração de tribos indígenas (oferta de presentes). Seriam as leis da hospitalidade universais?

O que parece conspirar contra essa universalidade é o caso da China, um país de cultura milenar que só recentemente se abriu ao mundo e que, por isso, desenvolveu-se sob paradigmas diferentes de outros povos, a quem sempre consideraram bárbaros. Como nota o sinólogo Rainier Lanselle (2011, p.221) nenhuma noção, nenhum termo, nenhuma categoria constituída do pensamento ou da prática social corresponde "a esse cenário de hospitalidade que consta da tradição das demais nações estudadas, principalmente ocidentais". Em nenhum texto por ele consultado, foi encontrada menção ao receber como dever. Ao contrário até, o prazer de receber-ser recebido é crivado de interdições. Não há noção de vínculo. É claro que os chineses valorizam as práticas do bem receber e do ser bem recebido, mas não é o dever de receber e sim a noção de ordem contra o caos, através da obediência aos rituais. Ou se trata de alguém externo, com quem se comunica ritualmente, sem se envolver, ou o amigo com quem alguém literalmente se confunde (aquele que estava em mim e eu não sabia).

Mais importante que elucubrar sobre enquadramentos teóricos da hospitalidade é mostrar que há reações, agora culturais, a essas leis. Tome-se, por exemplo, a tese de Bessone (2015), para quem há necessidade de des-eticizar (déséthiciser) a noção de hospitalidade para dar conta dos desafios da imigração no mundo. De resto, como previsto pelo próprio Derrida, a incondicionalidade dificilmente cabe num estatuto político. Denuncie-se, contudo, que reduzir a hospitalidade a um problema administrativo, esquecendo todo contexto ético envolvido, é uma forma cômoda e ideologicamente comprometida de (não) resolver o problema humano dos atuais refugiados.

Para muitos também, a noção de assimetria da cena hospitaleira, o protagonismo do anfitrião sobre o hóspede, como lembrou Gotman (2013) para o cenário francês, é politicamente incorreta, uma desigualdade que vai contra os desígnios de igualdade da Modernidade.

Outra reação, desta feita, à obrigação de retribuir pode ser lida na moda crescente de substituir o "obrigado(a)" por "gratidão". A primeira reação foi contra uma espécie de disfunção gramatical. Como já ilustramos com a ajuda de Lauand (2019), na expressão obrigado(a), o beneficiado declara que está obrigado(a) a retribuir, o que está ausente na expressão "gratidão". 
Mesmo sem a pretensa universalidade, as leis não escritas da hospitalidade continuam a vigorar ao menos entre nós. o que mais as valoriza, talvez, é a imagem da hospitalidade como o arco-íris, sob a qual repousa - tal como imaginada por Jabès (1991) - o feixe de luz que resume a humanidade em todas as suas cores.

\section{REFERÊNCIAS}

Augé, Marc (2010). Por uma antropologia da mobilidade. Ed.UNESP

Benveniste, E. (1975). O vocabulário das instituições indo-europeias. Economia, parentesco, sociedade. Campinas: UNICAMP.

Bessone, Magali (2015). Le vocabulaire de l'hospitalité est-il républicain? Ethique Publique, 17(1), s/p https://doi.org/10.4000/ethiquepublique.1745

Borradori, Giovana (2004). Filosofia em tempo de terror: diálogos com Habermas e Derrida. Zahar.

Bourdieu, Pierre (1996). Razões práticas. Sobre a teoria da ação. Papirus, 1996.

Buber, Martin (1979). Eu e Tu. Cortez \& Moraes, 1979

Camargo, Luiz, O.L. (2015). Os interstícios da hospitalidade. Revista Hospitalidade. 12 (especial), p. 48-69.

Camargo, Luiz, O.L. (2019). Hospitalidade, turismo e lazer. RBTUR, 13 (3), p. 1-13 https://doi.org/10.7784/rbtur.v13i3.1749

Derrida, Jacques. (1999) Manifeste pour I’hospitalité. Grigny: Paroles d`Aube.

Derrida, Jacques. (1997) II n`y a pas de culture ni de lien social sans um principe d`hospitalité. Le Monde, mardi 2 décembre 1997(Horizons-entretiens).

Dumazedier, Joffre (1995). A revolução cultural do tempo livre. Studio Nobel, 1995

Éliade, Mircéa (2010). História das crenças e das ideias religiosas: Volume 1: Da Idade da Pedra aos mistérios de Elêusis. Zahar.

Elias, Norbert (1994). O processo civilizador. 2 vols. Zahar

Engels, Friedrich (2002). A origem da família, da propriedade privada e do Estado. Bertrand Brasil.

Dumazedier, Joffre. A revolução cultural do tempo livre. Studio Nobel, 1995

Friedman. Georges (1972). O trabalho em migalhas. Perspectiva

Godbout, Jacques (1997). Récevoir c’est donner. Communications, $\quad 65, \quad$ p. $35-48$. https://doi.org/10.3406/comm.1997.1985

Gotman, Anne (2008). 0 turismo e a encenação da hospitalidade. In: Bueno e Camargo. Cultura e consumo: estilos de vida na contemporaneidade. Senac, p. 115-134

Gotman, Anne. (2009) O Comércio da Hospitalidade é Possível? Revista Hospitalidade, v. 6 (2), p. 3-27

Gotman, Anne. (2011) Les perils de l'asymétrie. La mondialisation et la fin de l'étranger. Collège des Études juives de l'Alliance universelle, p.15-36

Guattari, Felix (1991). As três ecologias. Papirus.

Guimarães, Gilberto A. (2019) Hospitabilidade: avaliação das características e motivações que determinam a capacidade de ser hospitaleiro. Tese (Doutorado) - Universidade Anhembi Morumbi - Programa de Pós-Graduação em Hospitalidade.

Homero (2014). Odisséia. Cosac Naify. https://doi.org/10.1515/9783050095530

Jabès, Edmond (1991). Le livre de I’hospitalité. Gallimard.

Kant, Immanuel (1995). Fundamentação da metafísica dos costumes. Ed.70

Klossowski, Pierre (1995). Les lois de I’hospitalité. Galimard

Krippendorf, Jost (1989). Sociologia do turismo. Civilização Brasileira

Jabès, Edmond (1991). Le livre de I’hospitalité. Gallimard.

Lafargue, Paul (2000). O direito à preguiça. São Paulo: Hucitec 
Lanselle, Rainier (2011). A hospitalidade como o impensado. In: Montandon, A. (Org.) O livro da hospitalidade: Acolhida do Estrangeiro na História e nas Culturas. Senac, p. 221-245.

Lashley, Conrad (2015). Hospitalidade e hospitabilidade. Revista Hospitalidade, 12 (especial), p. 70-92.

Lauand, Jean (2019). “Obrigado”,“Perdoe-me”: a Filosofia de S. Tomás de Aquino Subjacente à nossa Linguagem do Dia-a-Dia. Revista Hospitalidade,16(2), p. 138-148 https://doi.org/10.21714/21799164.2019.v16n2.007

Le Bras, Hervé (2005). La démographie. Odile Jacob.

Leroi-gourhan, André (1964). O gesto e a palavra. 2 v. Ed.70.

Levinas, Emmanuel (1996). Autrement qu'être: au-delà de l'essence. Le livre de poche

Lugosi, Peter (2008). Hospitality spaces, hospitable moments: consumer encounters and affective experiences in commercial settings. Journal of Foodservice, 19, p. 139-149 https://doi.org/10.1111/j.1745-4506.2008.00092.x

Massignon, Louis (1987). L'hospitalité sacrée. Paris: Nouvelle cité

Mauss, Marcel (1974). Ensaio sobre a Dádiva - forma e razão da troca nas sociedades arcaicas. In: Sociologia e Antropologia. EPU/Edusp.

Nietzsche, Friedrich (1981). Assim falou Zaratustra. Civilização Brasileira

Perez, Daniel O. (2007). Os significados dos conceitos de hospitalidade em Kant e a problemática do estrangeiro. Konvergencias: filosofia y cultura en dialogo, 4 (15), p.23-34

Pitt-rivers, Julian (2012). The law of hospitality. HAU: Journal of Ethnographic Theory. 2(1), p. 501-517. https://doi.org/10.14318/hau2.1.022

Sanselle, Rainier (2011). A hospitalidade como o impensado. In: Montandon (org). O livro da hospitalidade. Senac, 2011, p.221-245

Schérer, René (1993). Zeus hospitalier: l'éloge de l'hospitalité. Armand Colin

Simmel,Georg. A metrópole e a vida mental. In: VELHO, Otávio (org.). O fenômeno urbano. Zahar Editores.

Simmel,Georg. 2004. Fidelidade e Gratidão e Outros Textos. Relógio D’Água.

Smith, V. (1977). Hosts and Guests: The Anthropology of Tourism. Oxford Basil Blackwell.

Urry, John. (2001) O olhar do turista. SESC/Studio Nobel

\title{
Informações do Autor
}

\author{
Luiz Octávio de Lima Camargo \\ Programa de Graduação em Turismo /USP-EACH. \\ E-mail: loctavio@usp.br \\ ORCID: http://orcid.org/0000-0002-2387-7214
}

